\title{
Appendix
}

\section{Transcription Conventions}

? a question mark indicates rising intonation

(I.O) parentheses containing a number indicate a pause and the number of seconds

(.) a period in parentheses indicates a micropausel, less than two-tenths of a second

a period indicates a falling intonation word underlining indicates emphatic speech

:: $\quad$ a colon indicates a lengthening of the sound that precedes the colon. Two colons indicate an extended lengthening of the sound.

$=\quad$ an equal sign indicates overlapping speech

( ) a pair of single parentheses with no text indicates a passage that was unclear in the recorded audio

(( )) double parentheses indicate the author's description of affect/ gesture and extended periods of laughter

(h) $\quad h$ and variations in parentheses indicates laughter

boldface boldface indicates a passage the author wishes to highlight for the reader

... ellipses indicate lines were omitted from transcription 
